\title{
EDITORIAL
}

\section{Can surgical outcomes be prevented by postoperative admission to critical care?}

\author{
Andrew Rhodes* and Maurizio Cecconi
}

Postoperative complications are hugely important for both the patient involved and also the health-care system that they develop within. Potentially disastrous for the patient, they cause prolonged lengths of stay and can be an expensive problem to resolve. Indeed, recent data suggest that these costs may not just be relevant to the short-term hospital stay but may result in significant increased costs for the longer term following repeated hospital admissions and chronic ill health [1-4]. The prevention of these complications is thus of the utmost importance for anyone caring for this group of patients. This involves developing systems that can avoid the complications occurring in the first place and then to identify and rapidly treat the complications when they arise [5].

It has been estimated that up to 230 million surgical procedures are performed each year in the world [6]. If we consider patients undergoing non-cardiac surgery, up to $4 \%$ may die [7], and a significant portion more will develop postoperative complications [8] with a prolonged duration of hospital stay and a reduced longer-term survival [3]. Although for the majority of surgical patients, the risks of complications are low, for a significant number this is not the case $[9,10]$. In major surgery, even in groups with a low mortality rate, the incidence of postoperative complications is disproportionately high. The identification of risk for these patients is not straightforward. Important factors can be grouped into one of a number of main categories: first, those that are present prior to surgery that include the co-morbid status and age of the patient and the type and urgency of the surgery performed and, second, the physiological derangement of the patient at the end of the surgical procedure [10]. Many other strategies and markers of physiological status are currently being examined in order to identify the risks involved and to better prioritize available resources to individual patients [11].

*Correspondence: andyr@sgul.ac.uk

Department of Intensive Care Medicine, St George's Healthcare NHS Trust and St George's University of London, London SW19 0QT, UK
It has been estimated that in the UK $12 \%$ of all patients undergoing surgery account for almost $80 \%$ of all complications and deaths [12]. These figures from 2006 were recently confirmed within the UK together with the suggestion that this pattern is also prominent in many other European countries [7]. Clearly, better identification of this group of patients would enable evidencebased, resource-rich strategies to be directed toward this needy group who would be most likely to benefit. Patients are not receiving homogenous standards of care to identify and minimize the perioperative risk; even more, when complications occur, data suggest that different health-care systems react in different ways, leading to very different outcomes [5].

One strategy would be to admit all postoperative patients to an intensive care environment following surgery to enable them to have any of a number of evidence-based interventions in order to improve their outcome $[8,13,14]$. The problem with this approach is that these beds are often unavailable and that this course mandates an expensive strategy that may not be affordable in all health-care environments. The most appropriate use of this limited bed stock is thus very important. Clearly, it is neither possible nor desirable for every surgical patient to be admitted to critical care following surgery. Even if this were thought to be necessary, the capacity to deliver on this process is often not present. In 2006, it was estimated that $75 \%$ of surgical patients developing postoperative complications were neither cared for in a critical care environment nor referred back into the service [12]. These numbers do not seem to have improved significantly since then [7]. If these patients are now expected to be admitted to intensive care as a routine measure postoperatively, then the numbers of patients would quickly overwhelm most hospitals' critical care services.

Across Europe, there is a marked heterogeneity in the numbers of critical care beds within each country, even when the numbers are corrected for population size $[15,16]$. Estimates suggest that Germany has almost five times the number of critical care beds as the UK $[15,16]$. Even if these numbers are exaggerated, there is still a marked discrepancy in the numbers of beds present 
between the two countries and this must reflect differences in practice patterns and seems also to reflect differences in outcomes [7]. Although these inferences are anecdotal and most likely reflect an association rather than causation, they should make us ask the questions of how, where, and why health care should be delivered in a particular way. Wunsch [17] recently gave an eloquent description of the 'Starling curve for intensive care', in which the benefits and harms of simply creating more beds are delineated. Clearly, we are faced with some interesting dilemmas. Which patients following surgery should be admitted to a higher level of care and what should we then do for them? In addition, if the answer is that more patients need treating in this fashion, how are we to deliver the increased capacity that this would necessitate? The solution to these problems involves a series of evidence-based, ethical, resource, and economic arguments. By openly discussing and debating these issues, we should begin to understand who should be treating these patients - and why and how - following their surgical insult.

\section{Competing interests}

The authors received lecture and consulting fees from LiDCO (London, UK) and Edwards (Irvine, CA, USA).

Published: 28 January 2013

\section{References}

1. Nathan DP, Brinster CJ, Jackson BM, Wang GJ, Carpenter JP, Fairman RM, Woo EY: Predictors of decreased short- and long-term survival following open abdominal aortic aneurysm repair in a large contemporary series. J Vasc Surg 2011, 54:1237-1243

2. Kamphues C, Bova R, Schricke D, Hippler-Benscheidt M, Klauschen F, Stenzinger A, Seehofer D, Glanemann M, Neuhaus P, Bahra M: Postoperative complications deteriorate long-term outcome in pancreatic cancer patients. Ann Surg Oncol 2011, 19:856-863.

3. Khuri SF, Henderson WG, DePalma RG, Mosca C, Healey NA, Kumbhani DJ, Participants in the VA National Surgical Quality Improvement Program: Determinants of long-term survival after major surgery and the adverse effect of postoperative complications. Ann Surg 2005, 242:326-341.

4. Rhodes A, Cecconi M, Hamilton M, Poloniecki J, Woods J, Boyd O, Bennett D, Grounds RM: Goal-directed therapy in high-risk surgical patients: a 15-year follow-up study. Intensive Care Med 2010, 36:1327-1332.
5. Ghaferi AA, Birkmeyer JD, Dimick JB: Variation in hospital mortality associated with inpatient surgery. N Engl J Med 2009, 361:1368-1375.

6. Weiser TG, Regenbogen SE, Thompson KD, Haynes AB, Lipsitz SR, Berry WR, Gawande AA: An estimation of the global volume of surgery: a modelling strategy based on available data. Lancet 2008, 372:139-144.

7. Pearse RM, Moreno RP, Bauer P, Pelosi P, Metnitz P, Spies C, Vallet B, Vincent IL, Hoeft A, Rhodes A; European Surgical Outcomes Study (EuSOS) group for the Trials groups of the European Society of Intensive Care Medicine and the European Society of Anaesthesiology: Mortality after surgery in Europe: a 7 day cohort study. Lancet 2012, 380:1059-1065.

8. Lees N, Hamilton M, Rhodes A: Clinical review: goal-directed therapy in high risk surgical patients. Crit Care 2009, 13:231.

9. Findlay G, Goodwin A, Protopappa K, Smith N, Mason M: Knowing the Risk: A Review of the Peri-operative Care of Surgical Patients. London: National Confidential Enquiry into Patient Outcome and Death (NCEPOD); 2011.

10. Rhodes A, Moreno RP, Metnitz B, Hochrieser H, Bauer P, Metnitz P. Epidemiology and outcome following post-surgical admission to critical care. Intensive Care Med 2011, 37:1466-1472.

11. Pearse RM, Holt PJ, Grocott MP: Managing perioperative risk in patients undergoing elective non-cardiac surgery. BMJ 2011, 343:d5759.

12. Pearse RM, Harrison DA, James P, Watson D, Hinds C, Rhodes A, Grounds RM, Bennett ED: Identification and characterisation of the high-risk surgical population in the United Kingdom. Crit Care 2006, 10:R81.

13. Hamilton MA, Cecconi M, Rhodes A: A systematic review and meta-analysis on the use of preemptive hemodynamic intervention to improve postoperative outcomes in moderate and high-risk surgical patients. Anesth Analg 2010, 112:1392-1402.

14. Squadrone V, Coha M, Cerutti E, Schellino MM, Biolino P, Occella P, Belloni G, Vilianis G, Fiore G, Cavallo F, Ranieri VM; Piedmont Intensive Care Units Network (PICUN): Continuous positive airway pressure for treatment of postoperative hypoxemia: a randomized controlled trial. JAMA 2005, 293:589-595.

15. Wunsch H, Angus DC, Harrison DA, Collange O, Fowler R, Hoste EA, de Keizer NF, Kersten A, Linde-Zwirble WT, Sandiumenge A, Rowan KM: Variation in critical care services across North America and Western Europe. Crit Care Med 2008, 36:2787-2793.

16. Rhodes A, Ferdinande P, Flaatten H, Guidet B, Metnitz PG, Moreno RP: The variability of critical care bed numbers in Europe. Intensive Care Med 2012, 38:1647-1653.

17. Wunsch $\mathrm{H}$ : Is there a Starling curve for intensive care? Chest 2012, 141:1393-1399.

doi:10.1186/cc11687

Cite this article as: Rhodes A, Cecconi M: Can surgical outcomes be prevented by postoperative admission to critical care? Critical Care 2013, 17:110. 